\title{
Evaluation of capabilities of IR passive system for location of airborne objects
}

\author{
by Z. Bielecki, K. Chrzanowski, J. Piotrowski*», Z. Zawadzki \\ *Military University of Technology, Institute of Optoelectronics, 2 Kaliski St., 00-908 Warsaw, Poland, \\ e-mail:zbieleck@wat.waw.pl \\ **Vigo System Ltd., 11a Wyki St., 01-318 Warsaw, Poland, e-mail: jpiotr@vigo.com.pl
}

\begin{abstract}
:
A simple and low cost IR surveillance device based on a single, thermoelectrically cooled detector working in 3-5 $\mu \mathrm{m}$ spectral band is presented. Despite its simplicity, preliminary estimations of its detection range show its sufficient effectiveness in detection of airborne objects seeing abeam or aft.
\end{abstract}

\section{Introduction}

Up till now radars continue to be the chief group of surveillance systems detecting and locating airborne objects. Their main advantages are very long ranges of operation little dependent on atmospheric condition and possibility of 3-D location of the target (azimuth angle, elevation angle, distance) with Doppler measurement of its radial velocity. However, active character of radar operation limits its use, making them easy to find and, consequently, vulnerable. As a result, there is manifested a growing interest in passive IR systems detecting and locating airborne objects, because such systems can supplement or replace short-range radars.

There are already commercially available passive IR systems like Pilkington Optronics Air Defence Alerting Device (ADAD) or Saab IRS-700 Surveillance and Acquisition System [1]. Typical detection ranges of the systems are 10 to $15 \mathrm{~km}$ for fixed-wing and 6 to $9 \mathrm{~km}$ for rotary-wing aircraft. The systems consist of a self-contained infrared unit and a control and display unit which may be remotely located. They are built using a large TDI linear array of MCT detectors cooled by split-cycle Stirling coolers and they employ sophisticated electronics to improve range of detection and reduce probability of false alarms. Because of complex design the systems are expensive what limits their wide spread use. Therefore, simpler and low cost systems using a single, thermoelectrically cooled detector could be an interesting alternative.

Under assumption that such a surveillance system is positioned on remote alerting posts, detection and location of airborne targets seeing abeam or aft seems to be quite satisfactory. It means that the main source of thermal radiation is no longer a low-temperature, aerodynamically heated fuselage, but such high-temperature elements like engine exhaust nozzle and plume or these parts of aircraft fuselage that are heated by the plume. Such hightemperature sources make it possible to use 3-5 $\mu \mathrm{m}$ detectors instead of 8-12 $\mu \mathrm{m}$ detectors [2-5], what significantly reduces the cost of infrared sensor unit. Moreover, a single detector does not need a rotating prism system compensating image rotation.

\section{Description of the device}

A model of an IR device for location of airborne objects based on a single thermoelectrically cooled detector was designed in Institute of Optoelectronics MUT. It consists of separate scanning, thermodetection, control, and data acquisition and visualisation modules (Fig.1).

The device scans a $360^{\circ} \times 20^{\circ}$ sector in 1 second. Accuracy of location of the detected 
object is equal to $\pm 1^{\circ}$. The scanner (Fig.2) consists of a single mirror, which rotates horizontally with high speed and simultaneously swings vertically. Stabilised rotation is driven by DC motor, while swing is obtained with stepping motor and worm gear. Operation principle of rotational speed stabiliser is presented in Fig. 3.

The device can work with two replaceable thermodetection modules consisting of silicongermanium focusing objective, a detector with thermoelectric cooler and low-noise preamplifier (Fig.4). Vigo System PDI-2TE-4 photovoltaic detector is optimised for 2-4.2 $\mu \mathrm{m}$ spectral band, while EG\&G Judson 15TE4-3CN photoresistor is optimised for 2-5 $\mu \mathrm{m}$ spectral band. The detectors differ in their operating temperatures $\left(-65^{\circ} \mathrm{C}\right.$ for Vigo detector and $-80^{\circ} \mathrm{C}$ for Judson detector), active areas $\left(1 \mathrm{~mm}^{2}\right.$ and $0.0625 \mathrm{~mm}^{2}$ respectively) and detectivities (peak detectivity $\mathrm{D}^{*}$ equal to about $3 \cdot 10^{10} \mathrm{~cm} \cdot \mathrm{Hz}^{1 / 2} \mathrm{~W}$ and $6 \cdot 10^{10} \mathrm{~cm} \cdot \mathrm{Hz}^{1 / 2} \mathrm{~W}$ respectively). In the further text the device with PDI-2TE-4 detector is called variant $A$, as the device with 15TE4-3CN detector is called a variant $B$.

Data acquisition, preliminary processing and visualisation is performed by $\mathrm{PC}$ with graphic card and PCL-816 Data Acquisition Card (Advantech). The specialised software working on the Windows 95/98 platform and using Advantech DLL libraries was designed. Architecture of the data acquisition and visualisation system is shown in Fig.5.

\section{Estimation of detection ranges for aircraft.}

Reliable estimation of detection ranges requires not only detailed characteristics of the device but signatures of targets as well. Final verification must be carried out during field experiments with use of real targets. However, it is possible to make a rough estimation based on less or more complex models of the targets $[6,7]$. Such simple analytic techniques provide a lower accuracy, but may be adequate for preliminary assessments of system performance.

The simplest calculations can be made using standard signatures represented by square surfaces with defined sizes and temperature. Assumed parameters of targets (a plane and a helicopter), background and atmospheric transmission are presented in Tab.1.

Table 1.

\begin{tabular}{|c|c|c|}
\hline Parameter & Airplane & Helicopter \\
\hline Area of the equivalent surface & $3.5 \mathrm{~m} . \times 3.5 \mathrm{~m}$. & $3.0 \mathrm{~m} \times 3.0 \mathrm{~m}$ \\
\hline $\begin{array}{c}\text { Temperature difference between the aircraft } \\
\text { and background }\end{array}$ & $10 \mathrm{~K}$ & $3 \mathrm{~K}$ \\
\hline Background temperature & \multicolumn{2}{|c|}{$273 \mathrm{~K}$} \\
\hline Atmosphere extinction coefficient & \multicolumn{2}{|c|}{$0.2 \mathrm{~km}^{-1}$} \\
\hline
\end{tabular}

The calculations were done using a simple mathematical model of IR system. In Tab. 2 there are presented detection ranges of variants $A$ and $B$, obtained on assumption that the detection range is defined by the SNR equal to 2.25. These results were later compared with the results from commercially available software PcSensat. The discrepancies were found below $5 \%$.

Table 2.

\begin{tabular}{|c|c|c|}
\hline & Variant A & Variant B \\
\hline Detection range for airplanes & $1.6 \mathrm{~km}$ & $4.6 \mathrm{~km}$ \\
\hline Detection range for helicopters & $0.8 \mathrm{~km}$ & $2.5 \mathrm{~km}$ \\
\hline
\end{tabular}

Estimated the above way detection ranges of the device seem to be very short and insufficient for use, but they apply to direct nose view or only slightly beam view i.e. the most disadvantageous aspects of aircraft. Therefore, more accurate analysis including dependence of the range upon the aspect angle of the detected aircraft are necessary. 
Simple examples of such calculations done for airplanes were published in handbooks $[6,7]$. Because of some differences in approach presented by authors of the handbooks, the estimation of the angular characteristics of detection range of the presented device bases on H.M.Macfadzean's additive model with slightly modified parameters reducing the mentioned differences. As IR radiation emitted by exhaust gases does not propagate well in the atmosphere, the adapted model consists of three sections characteristic for nose, beam and tail views and representing effects of aerodynamic heating on the forward fuselage, engine heating of the fuselage and the engine exhaust nozzle. The properties of the sections are shown in Tab. 3.

Table 3.

\begin{tabular}{|c|c|c|c|}
\hline Section & Area $\left[\mathrm{m}^{2}\right]$ & Temperature $[\mathrm{K}]$ & Emissivity [1] \\
\hline 1 & 3.0 & $300 \mathrm{~K}$ & 0.9 \\
\hline 2 & 1.5 & $450 \mathrm{~K}$ & 0.7 \\
\hline 3 & 1.0 & $800 \mathrm{~K}$ & 0.9 \\
\hline
\end{tabular}

The background (sky) temperature is taken as equal to $280 \mathrm{~K}$

The angular characteristics of detection range are presented in Fig. 6-7 and its values for three main aspects of the aircraft are as the following:

Table 4

\begin{tabular}{|c|c|c|}
\hline View & Range of variant A $[\mathrm{km}]$ & Range of variant B $[\mathrm{km}]$ \\
\hline fore & 1.0 & 3.2 \\
\hline abeam & 4.7 & 9.6 \\
\hline aft & 12.9 & 19.3 \\
\hline
\end{tabular}

\section{Conclusion.}

As we can see, the calculated ranges for nose (fore) view of the airplane are significantly shorter than the detection ranges of the ADAD or IRS-700 alerting systems. However, if we consider relative simplicity and potentially low cost of the developed system, we can conclude that the IR device based on a single thermoelectrically cooled detector can be an interesting solution for almost undetectable passive systems used for location of airborne objects. However, it should be emphasized that only results of field experiments can decide about the real utility of the device.

This research was supported by State Committee for Scientific Research.

\section{References}

[1] ATKIN K. (ed.), Jane's Electro-Optic Systems 1999-2000, Jane's Information Group Limited, Coulsdon, 293-294 (1999).

[2] FINDLAY G.A, CUTTEN D.A., "Comparison of performance of 3-5 and 8-12 $\mu \mathrm{m}$ infrared systems", Appl. Opt. 28, 5029-5037 (1989).

[3] JOHNSON R.B., "Relative merits of the 3-5 $\mu \mathrm{m}$ and 8-12 $\mu \mathrm{m}$ spectral bands" SPIE Proc., 917, 102-107 (1988).

[4] LONGSHORE R., RAIMONDI P., LUMPKIN M., "Selection of detector peak wavelength for optimum infrared systems performance”, Infrared Phys., 16, 639-647 (1976).

[5] JAEGER T., NORDBRYHN A., STOKSETH P.A., "Detection of low contrast targets at 5 $\mu m$ and $10 \mu m$ : a comparison", Appl. Opt., 11, 1833-1835 (1972). 
http://dx.doi.org/10.21611/qirt.2000.047

[6] MACFADZEAN R.H.M., Surface-Based Air Defence System Analysis, Artech House, Boston, 22-30 (1992)

[7] DUDZIK M.C., The Infrared and Electro-Optical Systems Handbook, vol.4, Electro-Optical Systems Design, Analysis, and Testing, Infrared information Analysis Center, Ann Arbor, and SPIE Optical Engineering Press, Bellingham, 299-342 (1993). 
http://dx.doi.org/10.21611/qirt.2000.047

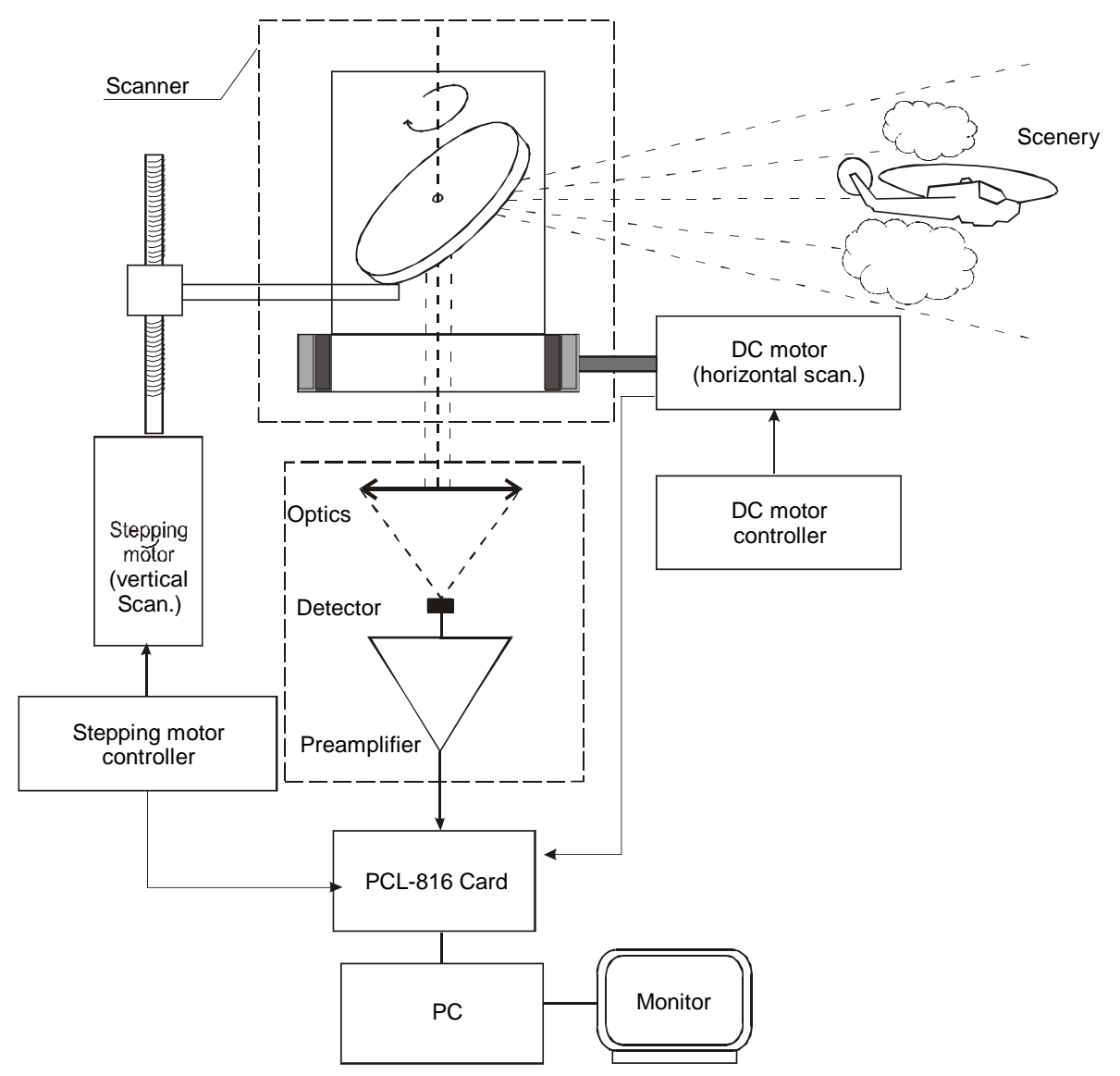

Figure 1. General architecture of the device.

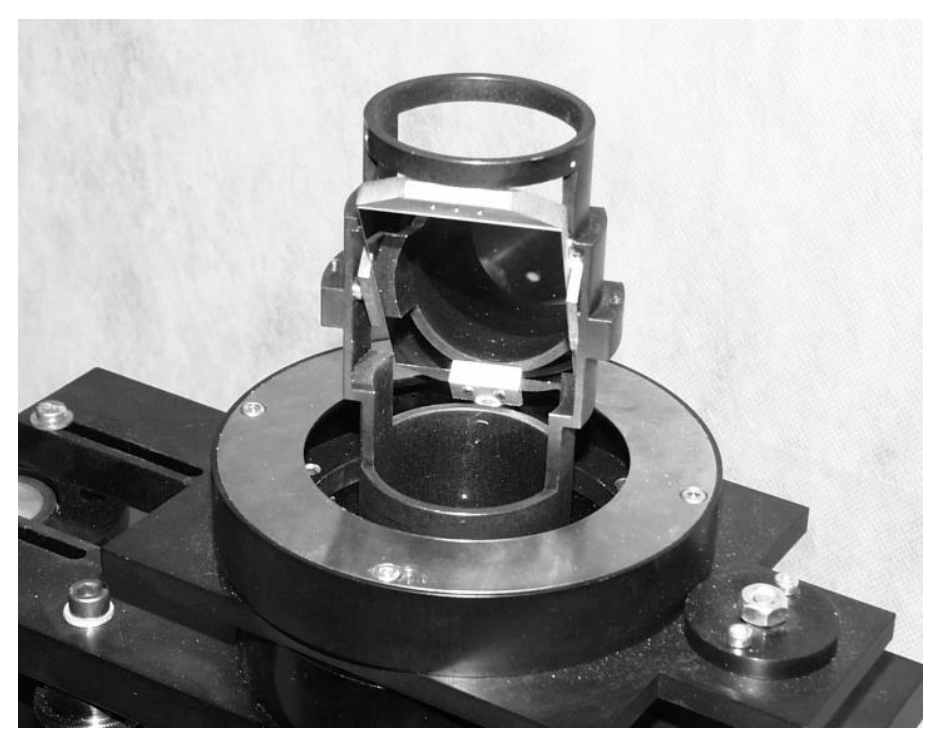

Figure 2. Scanning mirror. 


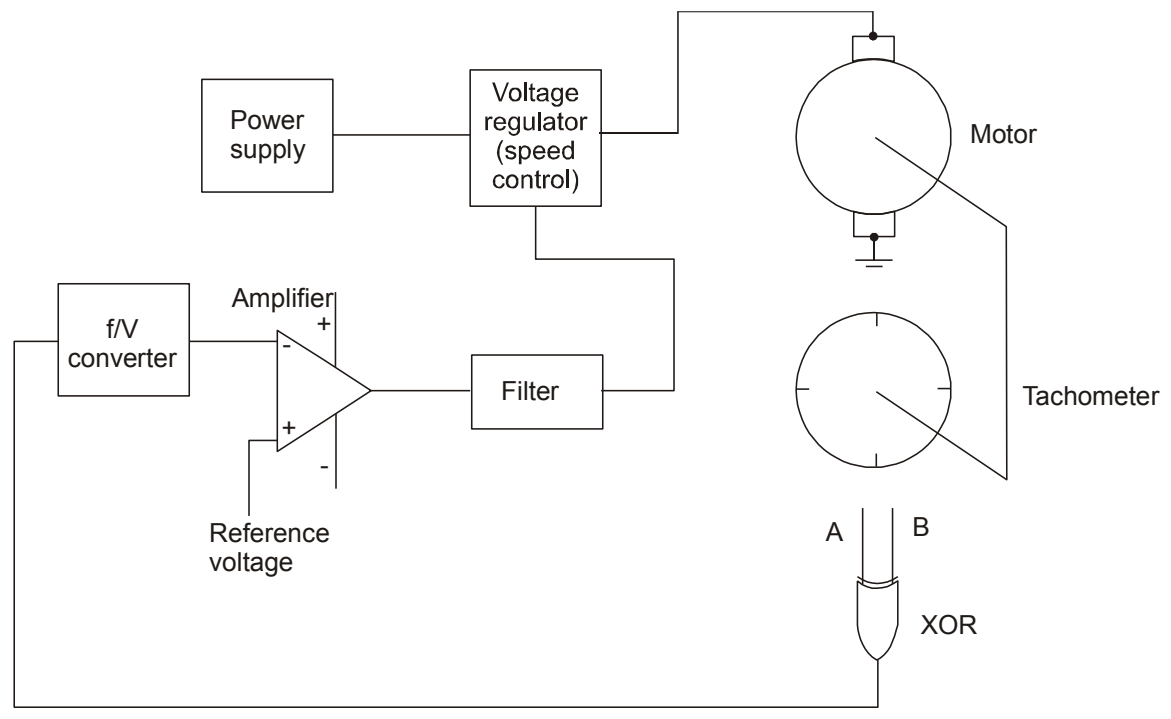

Figure 3. Block diagram of rotational speed stabilisation.

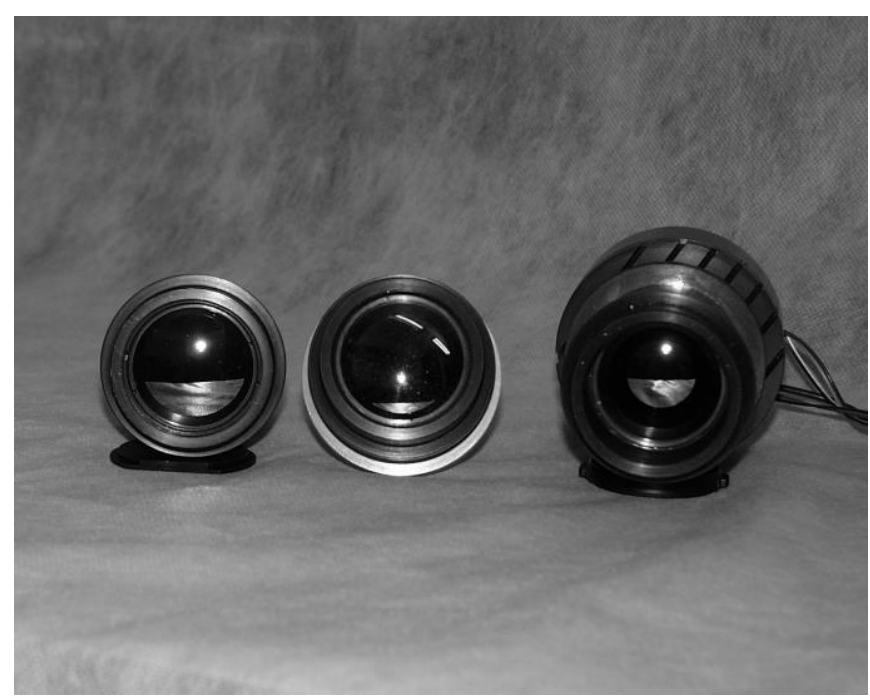

Figure 4. Thermodetection heads. 


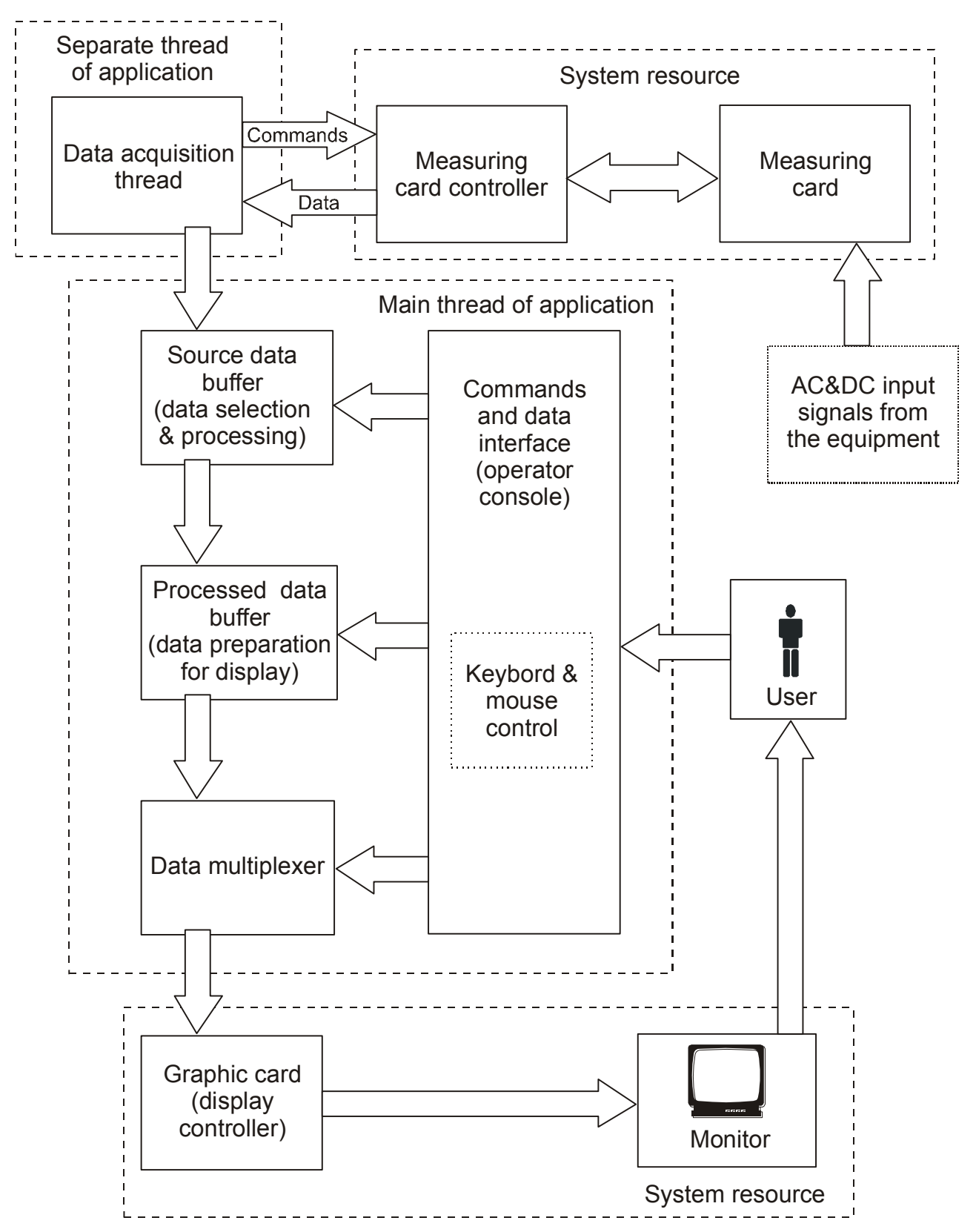

Figure 5. Block diagram of data acquisition and visualisation system. 


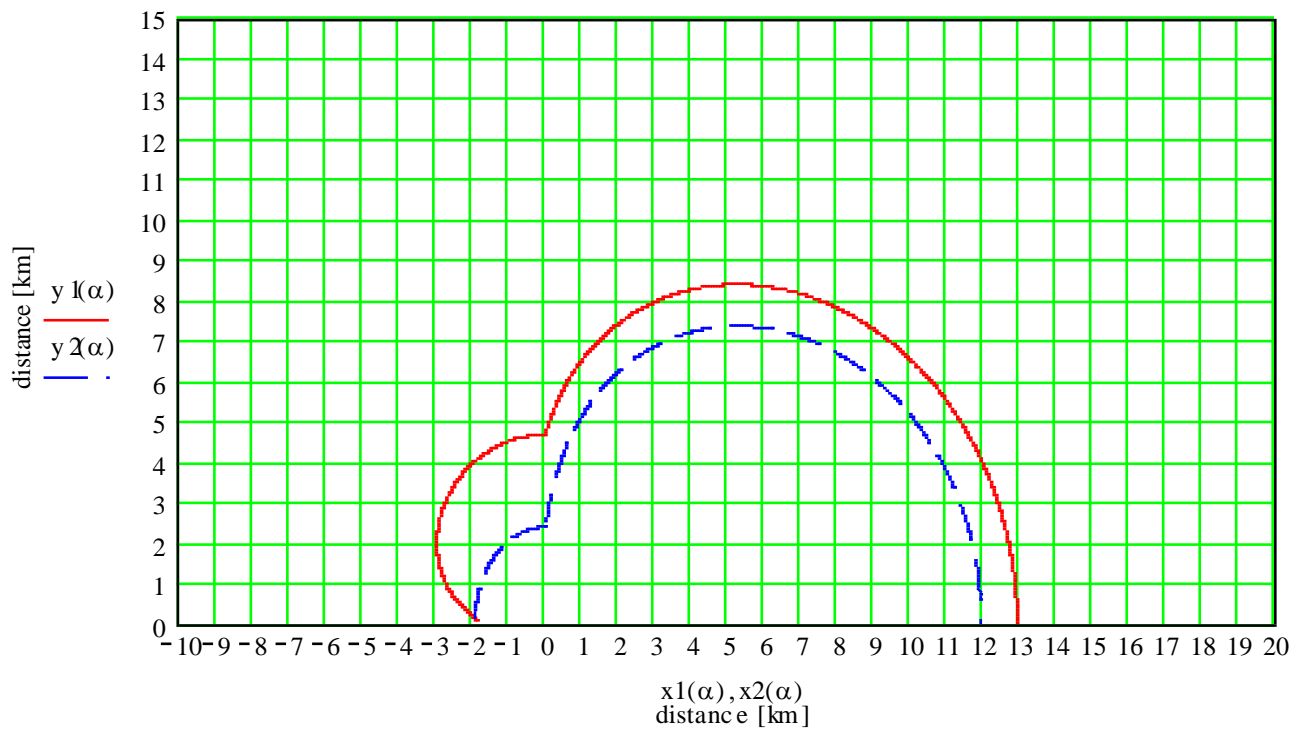

Figure 6. Horizontal range for detection of an airplane coming from left to right at altitude $0.2 \mathrm{~km}$ (solid line) and $4 \mathrm{~km}$ (dashed line). Version A.

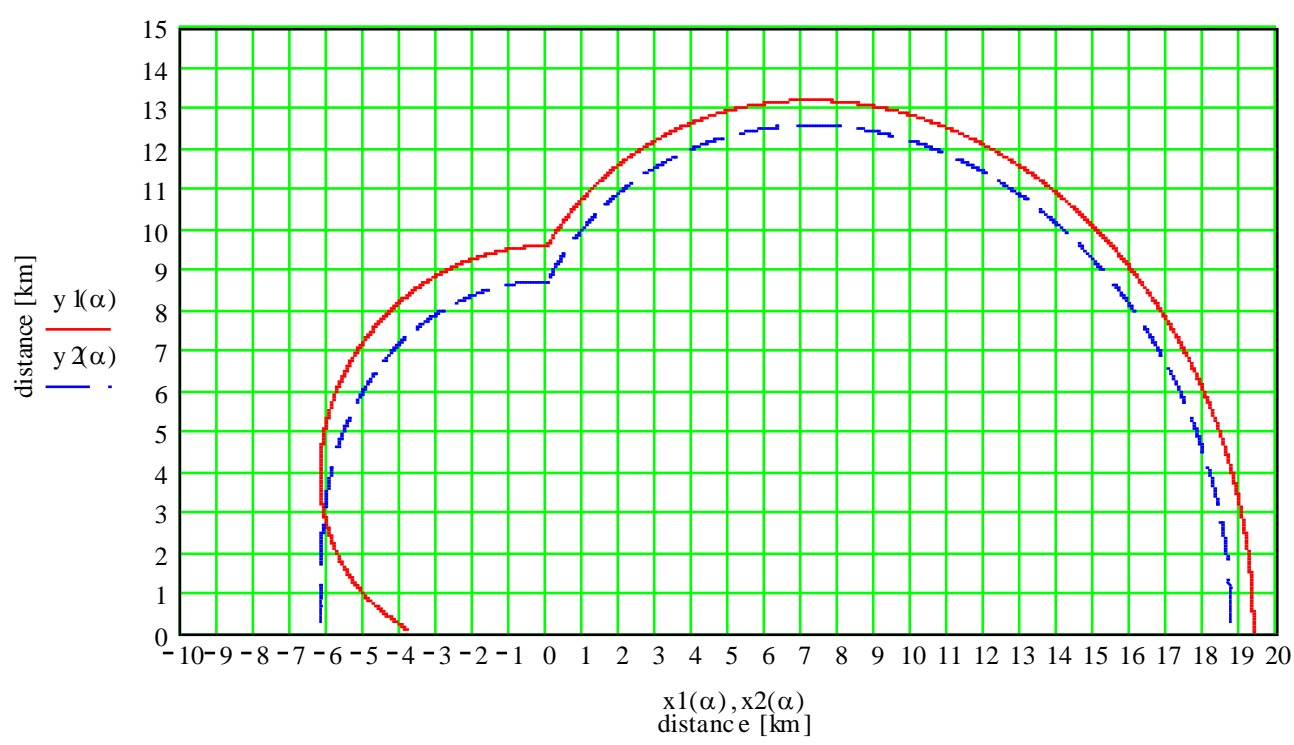

Figure 7. Horizontal range for detection of an airplane coming from left to right at altitude $0.2 \mathrm{~km}$ (solid line) and $4 \mathrm{~km}$ (dashed line). Version B. 